\title{
Erratum to: Hyperfine spin qubits in irradiated malonic acid: heat-bath algorithmic cooling
}

\author{
Daniel K. Park ${ }^{1,2}$ • Guanru Feng ${ }^{1,2}$ - Robabeh Rahimi ${ }^{1,2}$ • \\ Stéphane Labruyère $^{1}$. Taiki Shibata ${ }^{3}$. Shigeaki Nakazawa ${ }^{3}$. \\ Kazunobu Sato ${ }^{3}$. Takeji Takui ${ }^{3}$ - Raymond Laflamme ${ }^{1,2,4,5}$. \\ Jonathan Baugh ${ }^{1,2,6}$
}

Published online: 26 October 2015

(C) Springer Science+Business Media New York 2015

\section{Erratum to: Quantum Inf Process (2015) 14:2435-2461 DOI 10.1007/s11128-015-0985-1}

In subsection 3.2, "Continuous-wave ESR results", the Gaussian computer program should be cited as:

M.J. Frisch, G.W. Trucks, H.B. Schlegel, G.E. Scuseria, M.A. Robb, J.R. Cheeseman, G. Scalmani, V. Barone, B. Mennucci, G.A. Petersson, H. Nakatsuji, M. Caricato, X. Li, H.P. Hratchian, A.F. Izmaylov, J. Bloino, G. Zheng, J.L. Sonnenberg, M. Hada, M. Ehara, K. Toyota, R. Fukuda, J. Hasegawa, M. Ishida, T. Nakajima, Y. Honda, O. Kitao, H. Nakai, T. Vreven, J. A. Montgomery, Jr., J.E. Peralta, F. Ogliaro, M. Bearpark, J.J. Heyd, E. Brothers, K.N. Kudin, V.N. Staroverov, R. Kobayashi, J. Normand, K. Raghavachari, A. Rendell, J.C. Burant, S.S. Iyengar, J. Tomasi, M. Cossi, N. Rega, J.M. Millam, M. Klene, J.E. Knox, J.B. Cross, V. Bakken, C. Adamo, J. Jaramillo, R. Gomperts, R.E. Stratmann, O. Yazyev, A.J. Austin, R. Cammi, C. Pomelli, J.W. Ochterski, R.L. Martin, K. Morokuma, V.G. Zakrzewski, G.A. Voth, P. Salvador,

\footnotetext{
The online version of the original article can be found under doi:10.1007/s11128-015-0985-1.

Jonathan Baugh

baugh@uwaterloo.ca

1 Institute for Quantum Computing, University of Waterloo, Waterloo, ON N2L 3G1, Canada

2 Department of Physics and Astronomy, University of Waterloo, Waterloo, ON N2L 3G1, Canada

3 Department of Chemistry and Molecular Materials Science, Graduate School of Science, Osaka City University, Sumiyoshi-ku, Osaka 558-8585, Japan

4 Perimeter Institute for Theoretical Physics, Waterloo, ON N2J 2W9, Canada

5 Canadian Institute for Advanced Research, Toronto, ON M5G 1Z8, Canada

6 Department of Chemistry, University of Waterloo, Waterloo, ON N2L 3G1, Canada
} 
J.J. Dannenberg, S. Dapprich, A.D. Daniels, Ö. Farkas, J.B. Foresman, J.V. Ortiz, J. Cioslowski, and D.J. Fox, Gaussian 09, Revision A.02 (Guassian, Inc., Wallingford CT, 2009)

Figure 7 and its caption should be replaced by the following:

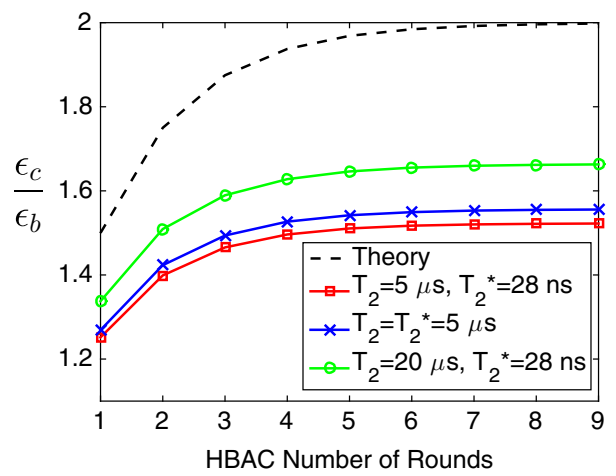

Fig. 7 Simulation results for 3-qubit HBAC using AHC. The plot shows the ratio of the $\mathrm{C}_{m}$ polarization $\left(\epsilon_{c}\right)$ and the electron bath polarization $\left(\epsilon_{b}\right)$ at the end of each HBAC round, up to 9 rounds. The dashed curve is the theoretical (ideal) value. The red (open squares) curve is obtained by incorporating all experimentally determined (room temperature) relaxation parameters. The blue (crosses) curve is obtained by allowing the $T_{2}^{*}$ of the electron to equal $T_{2}^{e}$. The green (open circles) curve is obtained by allowing $T_{2}^{e}$ to be $20 \mu \mathrm{s}, 4$ times longer than the measured value, in order to test the consequence of a longer electronic $T_{2}$

In the Acknowledgments section, we wish to add the following statement:

R.R. thanks S. Raesi for discussions. 